\title{
GROSS MOTOR PERFORMANCE AND THE EDUCATIONALLY SUB-NORMAL CHILD
}

\author{
L. BURWITZ* , P. W. Harrison *, Bruce DAVIEST, ANNE DAGGETTt and J. MONTGOMERY† \\ ${ }^{*}$ Crewe and Alsager College \\ tPreston Polytechnic
}

The present study is part of a long-term interdisciplinary project designed to study the apparent difference between normal and educationally sub-normal children (ESN) on tests that measure gross motor performance. The inferiority of ESN children in such tests as the AAHPER Youth Fitness Test is described as apparent since most studies reporting such a finding have compared a sample drawn from an ESN population with published age norms for normal children.

Several hypotheses have been offered to account for the apparent superiority of normal children. Howe (1959) suggests that the finding may be the result of higher motivation. It may be that the difference is a function of physical capacity per se. The ESN child may actually be at neurophysiological or biochemical disadvantage. Finally, it seems plausible from psychological evidence that the basis of the ESN child's poor performance is cognitive. Perhaps ESN children do not have the mental capacity to coordinate motor actions, whereas normal children achieve sequential and temporal organisation efficiently. Organised physical activity improves the gross motor performance of ESN children, due perhaps to increased motivation, physical capacity, cognitive awareness or a combination of all these.

The purpose of the present study was two-fold. First, a comparison was made between ESN and normal children on eight tests of gross motor performance to determine if the ESN children were inferior. Secondly, a training programme, stressing the cognitive elements of the various tests, was administered to determine whether improvements in performance were produced without an increase in physical capacity per se.

\section{METHOD}

Eight gross motor performance tests were administered to twelve ESN boys from Crookhey Hall Residential School, Preston, and to twelve normal boys from Ribbleton Hall School, Preston. The first five tests were from the AAHPER Youth Fitness Test, and comprised: Modified pull-ups, sit-ups in 30 seconds, 50 yard sprint, $4 \times 30$ feet shuttle run (with wooden blocks), left and right hand grip, standing broad jump, and onefoot balance with eyes shut. The group practised for 14 one-hour sessions over a four-week period. The cognitive aspects of each skill were stressed and at no time did any child appear to extend himself beyond a level equivalent to $25 \%$ of his initial performance.

The post-test took place on the day following the completion of practice, using the same trained examiners, and the children were assigned randomly to a test order.

\section{RESULTS AND DISCUSSION}

The data, which were analysed using a $2 \times 2 \times 2$ ANOVA (IO level $x$ practice treatment $x$ trials) with repeated measures on the final factor (Winer, 1962), revealed the main effect (Practice vs Control) was not significant in any of the tests - practice did not improve physical capacity.

The 10 level (ESN vs Normal) main effect was significant $(p<0.05)$ on sit-ups, 50 yard sprint and shuttle run; marginally significant ( $p<0.07$ ) on pull-ups and right-hand grip; non-significant on left-hand grip and standing broad jump. The superiority of the normal children was greater apparently on those items which required more complex actions. Perhaps ESN children can organise actions involved in a discrete skills, such as the standing broad jump, but not those required for the coordinated performance of a more continuous skill involving actions which require feed-back. Additional information to confirm this hypothesis is being collected from biomechanical film analysis of the standing broad? jump and burpees tests.

The trials (Pre- vs Post-test) main effect was significant $(P<0.05)$ on all test items other than pull-ups. The post-test scores were always better than those of the pre-test except in the case of the two hand-grip tests where the opposite occurred. The main effect on pullups was non-significant, largely due to the deterioration of the ESN Control treatment, and this supports the hypothesis that cognitive practice facilitates the gross motor performance of ESN but not of normal children. This differential effect of pull-up practice was not sufficiently strong to produce a significant 10 level $x$ Practice treatment $x$ Trials interaction $(F=1.40, d f=1.44, p$ $<0.10)$.

Interaction with the shuttle-run was significant $(F=$ 3.46, $\mathrm{df}=1.44, \mathrm{p}<0.08$ ). Post-hoc analysis revealed once again that the Normal Control, Normal Practice and ESN Practice treatments improved, while the ESN Control condition deteriorated.

These hypotheses obviously require further attention. If' the ESN child is to have no physical disadvantage, he must be trained in those activities which can improve the cognitive aspects of his skills: practising the skill im proves their performance. This work is being continued, and will be published fully elsewhere. 